\title{
Breast Cancer in Women under 30 is Highly Aggressive with Extremely Low Frequency: A Case Report
}

\author{
Paun $\mathrm{I}^{1 *}$, Ionescu $\mathrm{M}^{2}$, Paun $\mathbf{M}^{3}$, Costin $\mathrm{A}^{1}$, Vidrighin $\mathrm{C}^{1}$, Florescu $\mathbf{M}^{1}$, Mogos $\mathrm{D}^{1}$ and Costantin $\mathrm{V}^{4}$ \\ ${ }^{1}$ Surgery Unit, Cf Craiova Hospital, 6 Stirbei Voda Street, Romania \\ ${ }^{2}$ Oncology Unit, Graal Craiova hospital, 6 Stirbei Voda Street, Romania \\ ${ }^{3}$ Obstetrics and Gynecology Unit, Memorial Hospital of Craiova, 6 Stirbei Voda Street, Romania \\ ${ }^{4}$ Surgery Unit, St. Pantelimon Clinic Hospital, Bucharest, Romania
}

Received: August 04, 2014; Accepted: September 11, 2014; Published: October 08, 2014

*Corresponding author: Ion Paun, Surgery Unit, CfCraiova Hospital, 6 Stirbei Voda Street, Romania, Tel: +0723-347572; E-Mail: dripaun@gmail.Com

\begin{abstract}
Breast cancer occurrence is increasing worldwide; however, patients under 30 years of age who present with this condition are scarce. Using as a pretext, the "chance" to encounter a case of breast cancer patient less than 30 years of age in a hospital setting, in conjunction with the relatively few data in the literature on the topic, the current paper attempts to point out some of the features of breast carcinoma occurring in this category of patients. Basically, the paper highlights a very important aspect, namely that breast carcinoma in young women is more aggressive and shows a reserved prognosis, translated as a 5-year lower survival rate and a higher percentage of relapse following therapy compared to women in perimenopause or to elderly ones.
\end{abstract}

Keywords: Breast cancer; Young women; Low frequency; Reserved prognosis

\section{Introduction}

The current paper does not aim to analyze or draw conclusions on the behavior of breast cancer in young and very young (under 30 years old) women, nor is it supposed to do it based on solely one case in the context of extremely low occurrence of the disease in these age [1]. Nevertheless, due to the very occurrence of the case and the related trauma, in conjunction with relatively few papers on the topic, we attempted to point out some of the characteristics of breast carcinoma in the target population, which prove to be a slightly different in comparison to the "classical" data of the other age [2]. Last but not least, we intend this paper to be a plea in favor of accurate briefings of young women concerning the risks related to the existence of malignant lesions in the breast, in particular period of life, and to increase the awareness of the medical profession detecting the mammary tumor in this category of women.

\section{Case Report}

Patient IP, aged 27, from Craiova, is hospitalized on November 13,2008 on account of right breast diffuse enlargement. On clinical examination: diffusely enlarged right breast, with erythema and edema of the skin, showing a thick consistency in the central and lower quadrants, being sensitive to touch. 3 palpable lymph nodes were found in the right armpit, having a diameter between $1 \mathrm{~cm}$ and $2.5 \mathrm{~cm}$, with a thick consistency. Ultrasonography revealed the presence of a non-homogenous glandular tissue of the right breast, with four solid nodes, non-homogeneous, with unclearly defined calcifications, vascular signal of low strength visible centrally and peripherally, highly suggestive of their equivocal character; the nodes had the following size: $2.8 / 2 \mathrm{~cm}, 1.7 / 1.3 \mathrm{~cm}$, $1.5 / 1 / 0.1 \mathrm{~cm}$ and $1 / 0.7 \mathrm{~cm}$, in the right armpit lymph nodes were found, having diameters of $\max =20 \mathrm{~mm}$, with non-differentiated sinus and periphery, and arterial vascular signal of low strength. Bone scintigraphy did not reveal the presence of bone lesions.

Laboratory tests indicated: $\mathrm{Hb}=13.2 \mathrm{~g} \%, \mathrm{WBC}=11720 /$ $\mathrm{mm}^{3}$, Urea $=36 \mathrm{mg} \%, \mathrm{Bt}=0.26 \mathrm{mg} \%$ and CA 15-3 $=40.3 \mathrm{U}$. Chest X-ray revealed no damage evolution. On November 15, 2008 axillary lymph node biopsy was done. The histopathological test confirmed a poorly differentiated massive metastatic carcinoma. The immunohistochemical test revealed the following: HER2negative, ER-negative, PGR-positive in less than $10 \%$ of the tumor cells and SR-2 (positive). The diagnosis upon discharge was: breast cancer (inflammatory carcinoma)-stage III B (T4dN2M0) [3]. In January 2009 the patient was referred to the Oncology unit where she was given chemotherapy in 5 sequences (DOCETAXEL and EPIDOXORUBICIN) [4,5]. The response to chemotherapy was partial: the erythema wore off and the skin edema was reduced (yet a slight peau d'orange was still present). Also a right axillary lymphadenopathy relic having a diameter of $1.5 \mathrm{~cm}$ persisted. Under the circumstances, it was decided to change the regimen by administering EPIDOXORUBICIN +5 FLUOROURACIL + CYCLOPHOSPHAMIDE [4,5] in 4 sequences, followed by radiotherapy $50 \mathrm{~Gy}$, the evolution still being favorable (disappearance of skin edema with the involution of mammary lymph nodes and axillary adenopathy). On 22 July 2009 surgery took place in the form of mastectomy with full axillary dissection.

The histopathological result of 12 August 2009 revealed the following: macroscopically-four tumors having the size of 2/1.6 
$\mathrm{cm}, 1.1 / 1 \mathrm{~cm}, 0.9 / 0.8 \mathrm{~cm}$ and $0.5 / 0.3 \mathrm{~cm}$, respectively, depth of resection of $1.2 \mathrm{~cm}$; microscopically - post-chemotherapy and radiation tumor relic resembling lobular infiltrating carcinoma coexisting with ductal infiltrating carcinoma, fibro-hyaline stroma, extensive necrosis, moderate lymphocyte infiltration, intra lymphatic invasion. No perineural invasion was identified, and the nipple was free of tumor. Four axillary lymph nodes showed metastatic disease. Starting from August 2009, the patient complained of persistent headache, vertigo-which is why she was referred for a cranial MRI, which indicated the presence of secondary brain and left parietal tumors, therefore, during August 24, 2009 to September 18, 2009 she undertook craniocerebral radiotherapy with 27 Gy. She was administered Cisplatin and Gemcitabine in six sequences in the Oncology unit. Starting from April 2010, the patient complained of right hemithorax pain, the chest X-ray revealed a round-oval opacity of 5.6/3.7 cm relatively well-defined, with lysis of the straight rib curves C5C6, extending to the soft tissue at this level (secondary lesion). Treatment with Zoledronic Acid (ZOMETA) was administered, followed by Avastin (BEVACIZUMAB) in May 2010. The CT scan of the spine on 17 June 2010 highlighted the secondary tumors in the lower thoracic, lumbar and first sacral vertebra level. The patient died on 3 July 2010 with acute pulmonary edema.

\section{Discussion}

Breast cancer occurrence is increasing worldwide, with the largest number of cases being reported during perimenopause $[1,2]$. Conversely, both literature and current practice shows that patients with breast cancer are rare under the age of $30[1,2,6]$. Using as a pretext the "chance" to encounter such a case in the hospital and relating it to the information provided by literature, we attempted to point out some of the peculiarities and paradoxes of the disease course in young women. The majority of breast tumors occurring in adolescent and young women are benign, and out of these, fibroadenomas are the most common, their occurrence ranging between $44 \%$ and $94 \%$, according to various reports $[7,8]$. The frequency of breast malignancy occurring in women under the age of 30 , this is very low ranging between 0 and 9.5\% [9-11]. The most common malignancies occurring in these patients are stromal tumors, such as Phyllodes malignant fibroadenomas and metastatic tumors, usually multiple ones $[7,11,12]$.

The frequency of breast carcinoma occurring in young women varies according to different reports, however, all have a common core, namely the very low rate of this phenomenon as Simmons et al. [7] states that breast carcinoma occurring in young women represents $0.02 \%$ of all the excised breast tumors [8]. These findings published by the National Cancer Institute 's Surveillance, Epidemiology and Enol Results shows that out of the 77,368 women diagnosed with breast cancer only $1 \%$ were aged between 20 and 29 [1,3]. The statistics provided by the National Cancer Database of the American College of Surgeons indicate a $0.8 \%$ frequency of breast carcinoma occurring in women aged under 30 [9]. Kollias et al. [13] revealed a frequency of $1.1 \%$ women with breast cancer aged between 26 and 35 . Finally, in the UK, the frequency of breast carcinoma in women aged between 20 and 24 is $1.2 \%_{000}$, and of $3 \%_{000}$ [1] in women aged between 15 and 19 .

The small number of scientific reports on papers about breast cancer in young women and the small number of reported cases do not allow for the calculation of a highly accurate frequency of this disease in persons belonging to this age group. The second issue, and perhaps the most important, lies in the postulation that breast carcinoma in young women appears to be more aggressive and shows a reserved prognosis, resulting in a 5-year shorter survival rate and a higher percentage of recurrences following therapy, compared to women at perimenopause period or to the elderly $[8,14]$. According to many scholars, the young age itself is a negative prognostic factor for breast cancer, while other authors believe that the role of this factor is still controversial $[2,15,16]$. An important element that contributes to worsening the prognosis is represented by the delayed diagnosis of breast cancer $[8,17]$.

This delay is due, more often than not, to the patient, who does not palpate the breasts regularly or ignores the existence of clinical signs and the presence of a tumor mass in the breast, a mastalgia or blood leakage from the nipple.

Likewise, the desire of these women to be pregnant may delay the diagnosis, many breast cancers becoming clinically evident during gestation or immediately after delivery [18-20]. Hence, breast palpation, ultrasonography of breasts and armpits, and biopsy of the tumor tissue (punch biopsy) are considered to be the gold standard in the evaluation of masses occurring in a woman under 30 [14]. Particular importance should be attached to the information relating to personal history (other malignancies, undergoing radiant treatments or hormone replacement therapy) or to family history, with the presence of relatives with breast cancer or with bilateral breast cancer, colon cancer or other types of cancer. The diagnosis of breast cancer in young women associated with a family history of breast, ovarian or colon cancer raises suspicion of mutations in BRCA1 or BRCA2 genes $[4,21]$.

Some authors consider that about $10 \%$ of patients with breast cancer under the age of 40 are carriers of mutations in BRCA1 or BRCA2 [22].

The prognosis of breast cancer in young women is associated with the tumor size, metastatic disease in the lymph nodes, histological type, degree of cell differentiation and immunohistochemical markers $[1,23]$.

There are suggestions that the average size of primary tumors is higher in women under 35 years compared to other age groups, whereas other authors do not find such differences based on statistical data $[11,12,24,25]$.

Also, it is claimed that in young women the percentage of cases with multiple unilateral or bilateral mammary tumors is higher, with respect to the presence of the metastatic disease in axillary nodes, the majority of the statistics clearly indicate their higher frequency in young women compared to other age groups. In this climate of opinion, Bertheau reports a frequency 
rate of 65\% [26] and Walker goes for 69\% [27] in women under 30 years, Fisher et al. [28] identify a frequency rate of $60 \%$ in the case of the metastatic disease in axillary nodes in women under 39 years and Kim et al. [15] indicate a frequency of $48 \%$ of these metastases in women under 35. It was also the case of our patient, where four lymph nodes were invaded. Regarding the histological type of carcinoma occurring in young women in most of the reported cases the ductal infiltrating type prevails, and there are rare cases of lobular infiltrating carcinoma, as considered by pathologists as always having a low degree of cell differentiation (stage III) $[1,4,8,17,29]$.

As a peculiarity, we recorded the coexistence of the ductal infiltrating and lobular infiltrating carcinoma types in our patient, which, in our opinion, contributed to worsen the prognosis. Literature describes a particular form of secretary breast carcinoma, characteristic to childhood and adolescence and which usually has a favorable prognosis [1]. The analysis of the differentiation of tumor cells revealed the prevalence of stage III (very poor cell differentiation), followed by tumors of stage II of (moderate) cell differentiation, while emphasizing the quasiinexistence of tumor of stage I (well differentiated cells) $[1,30]$. In general, in breast cancer a number of immunohistochemical markers can be identified, which can be dosed and whose expression may have a predictive value of the prognosis. High levels of markers Ki-67 and low levels of the protein p27, as well as the over expression of the marker HER2 are associated with a reserved prognosis [23]. Mammary tumors of stage II and III of differentiation are associated, to a significant degree, with positive HER2 positive and high values of the marker Ki-67; there is instead a negative association with the estrogen receptors $\alpha$ and $\beta$ and high values of the protein p27 [31-34].

In women under 35 with breast carcinoma, low values of the estrogen and progesterone receptors, in contrast with the over expression of HER2 and high values of the marker Ki-67 and protein p 53 are frequent in immunohistochemical tests. This immunohistochemical description may explain in part the rather reserved prognosis of these patients with breast cancer $[4,35,36]$. The treatment of breast cancer occurring in women younger (under 30 years) is a complex one (surgery, chemotherapy, hormone therapy, radiotherapy) taking into consideration this mammary tumor aggressiveness and, of course, a range of parameters such as: stage, histological type, stage of differentiation or immunohistochemical markers. Similarly, toother age groups and young women, the type of surgery may be breast-conserving or radical, depending on local conditions and preferences of patients. Although a number of statistical studies identify a high rate of recurrence after breast-conserving surgery in young women compared to other age groups, the same authors state that the recurrence rate is the same whatever the surgery or mastectomy $[37,38]$. In spite of the fact that postoperative radiotherapy in the remaining breast reduces the rate of local recurrence, regardless of the age group, the rate remains higher in women aged under 40 [35,39]. Thus, Bartelink et al. [39] show a decrease in the rate of local recurrence in 10 years' time after surgery, from $24 \%$ to $14 \%$ in patients under the age of 40 undergoing radiotherapy in the remaining breast compared to a decrease from $7 \%$ to $4 \%$ in women older than 60 years [40].

Various empirical works reveal that hormone therapy with Tamoxifen $20 \mathrm{mg}$ daily for 5 years is a standard component of adjuvant systemic therapy in young women with breast tumors bearing hormone receptors for estrogen and progesterone $[32,39]$. This treatment significantly reduces the risk of recurrence of breast cancer in all age groups, but it seems that this risk is, however, slightly higher in women under the age of 35 compared to those between 35 and 49 years [4,5,41]. Also the 5 -year survival of patients younger than 35 years is significantly lower than that of other age groups. Specifically, Simmons et al. [1] indicated a 5 -year survival of $50 \%$ for patients aged under 25 , while Kothari et al. mentions a 5-year survival of $67 \%$ for patients aged under 35 [8]. Unlike the patients in perimenopause, the prognosis of breast cancer occurring in young and very young women is reserved both in terms of long-term survival and the recurrence rate, to which the quasi-inexistence of well-differentiated histological forms is added, all determining the selection of the most adequate loco regional and systemic treatment to maximize the chances of healing.

\section{Conclusion}

In conclusion, we can state that although the frequency rate of breast cancer in young women is very low, tumors occurring in these age groups, however, are more aggressive and show a more reserved prognosis than malignant breast tumors occurring during perimenopause.

\section{References}

1. Kothari AS, Beechey-Newman N, D’Arrigo C, Hanby AM, Ryder K, Hamed $\mathrm{H}$, et al. Breast carcinoma in women age 25 years or less. Cancer. 2002; 94(3): 606-614.

2. Winchester DP, Osteen RT, Menck HR. The National Cancer Data Base report on breast carcinoma characteristics and outcome in relation to age. Cancer. 1996; 78(8): 1838-1843.

3. Swanson GM, Lin CS. Survival patterns among younger women with breast cancer: the effects of age, race, stage, and treatment. J Natl Cancer Inst Monogr. 1994; 16: 69-77.

4. Francis PA. Optimal adjuvant therapy for very young breast cancer patients. Breast. 2011; 20 (4): 297-302. doi: 10.1016/j.breast.2011.05.002.

5. Goldhirsch A, Gelber RD, Yothers G, Gray RJ, Green S, Bryant J et al. Adjuvant therapy for young women with breast cancer need for tailored treatments. JMCI Monogr. 2001; 30: 44-51.

6. Jemal A, Bray F, Center MM, Ferlay J, Ward E, Forman D. Global cancer statistics. CA Cancer J Clin. 2011; 61(2): 69-90. doi: 10.3322/ caac.20107.

7. Jayasinghe Y, Simmons P. Breast disorders in the female. In: Fisher M, Alderman EM, Rosenfeld W, Kreipe RE, editors. AAP Textbook of adolescent health care. ERK Grove Village (IL): American Academy of Pediatrics; 2011. p. 322-329.

8. Simmons PS, Jayasinghe YL, Wold LE, Melton LJ 3rd. Breast carcinoma in young women. Obstet Gynecol. 2011; 118(3): 529-536. doi: 10.1097/AOG.0b013e31822a69db. 
9. Osteen RT, Cady B, Chmiel JS, Clive RE, Doggett RL, Friedman MA, et al. 1991 national survey of carcinoma of the breast by the Commission on Cancer. J Am Coll Surg. 1994; 178(3): 213-219.

10. Wu X, Groves FD, McLaughlin CC, Jemal A, Martin J, Chen VW. Cancer incidence patterns among adolescents and young adults in the United States. Cancer Causes Control. 2005; 16(3): 309-320.

11. Jayasinghe Y, Simmons P. Disorders of the young breast In: Altchek A, Deligdischl L editors. Pediatric. Adolescent and Young Adult Gynecology, Oxford (UK): Wiley Blackwell; 2009. p. 256-264.

12. Briggs RM, Walters M, Rosenthal D. Cystosarcoma phylloides in adolescent female patients. Am J Surg. 1983; 146(6): 712-714.

13. Kollias J, Elston CW, Ellis IO, Robertson JF, Blamey RW. Early-onset breast cancer--histopathological and prognostic considerations. Br J Cancer. 1997; 75(9): 1318-1323.

14. Shannon C, Smith IE. Breast cancer in adolescents and young women. Eur J Cancer. 2003; 39(18): 2632-2642.

15. Kim SH, Simkovich-Heerdt A, Tran KN, Maclean B, Borgen PI. Women 35 years of age or younger have higher locoregional relapse rates after undergoing breast conservation therapy. J Am Coll Surg. 1998; 187(1): 1-8.

16. Albain KS, Allred DC, Clark GM. Breast cancer outcome and predictors of outcome: are there age differentials? J Natl Cancer Inst Monogr. 1994; 16: 35-42.

17. Corpron CA, Black CT, Singletary SE, Andrassy RJ. Breast cancer in adolescent females. J Pediatr Surg. 1995; 30(2): 322-324.

18. Beadle BM, Woodward WA, Middleton LP, Tereffe W, Strom EA Litton JK, et al. The impact of pregnancy on breast cancer outcomes in women<or=35 years. Cancer. 2009; 115(6): 1174-1184. doi: 10.1002/ cncr.24165.

19. Richards MA, Westcombe AM, Love SB, Littlejohns P, Ramirez AJ Influence of delay on survival in patients with breast cancer: a systematic review. Lancet. 1999; 353(9159): 1119-1126.

20.Sainsbury R, Johnston C, Haward B. Effect on survival of delays in referral of patients with breast-cancer symptoms: a retrospective analysis. Lancet. 1999; 353(9159): 1132-1135.

21. Peto J, Collins N, Barfoot R, Seal S, Warren W, Rahman N, et al. Prevalence of BRCA1 and BRCA2 gene mutations in patients with early-onset breast cancer. J Natl Cancer Inst. 1999; 91(11): 943-949.

22. de Sanjosé S, Léoné M, Bérez V, Izquierdo A, Font R, Brunet JM, et al Prevalence of BRCA1 and BRCA2 germline mutations in young breast cancer patients: a population-based study. Int J Cancer. 2003; 106(4): 588-593.

23. Olsson A, Borgquist S, Butt S, Zackrisson S, Landberg G, Manjer J. Tumour-related factors and prognosis in breast cancer detected by screening. Br J Surg. 2012; 99(1): 78-87. doi: 10.1002/bjs.7757.

24. Bertheau P, Steinberg SM, Merino MJ. C-erbB-2, p53, and nm23 gene product expression in breast cancer in young women: immunohistochemical analysis and clinicopathologic correlation. Hum Pathol. 1998; 29(4): 323-329.

25. Gillett D, Kennedy C, Carmalt H. Breast cancer in young women. Aust $\mathrm{N}$ Z J Surg. 1997; 67(1): 761-764.

26. Bertheau P, Steinberg SM, Cowan K, Merino MJ. Breast cancer in young women: clinicopathologic correlation. Semin Diagn Pathol. 1999; 16(3): 248-256

27. Walker RA, Lees E, Webb MB, Dearing SJ. Breast carcinomas occurring in young women (<35 years) are different. Br J Cancer. 1996; 74(11): 1796-1800.

28. Fisher CJ, Egan MK, Smith P, Wicks K, Millis RR, Fentiman IS. Histopathology of breast cancer in relation to age. Br J Cancer. 1997; 75(4): 593-596.

29. Sariego J. Breast cancer in the young patient. Am Surg. 2010; 76(12): $1397-1400$.

30. Richards MA, Gregory WM, Smith P, Millis RR, Fentiman IS, Rubens $\mathrm{RD}$. Age as prognostic factor in premenopausal breast cancer. Lancet. 1993; 341(8858): 1484-1485.

31. Huang HJ, Neven P, Drijkoningen M, Paridaens R, Wildiers H, Van Limbergen E, et al. Association between tumour characteristics and HER-2/neu by immunohistochemistry in 1362 women with primary operable breast cancer. J Clin Pathol. 2005; 58(6): 611-616.

32. Dunnwald LK, Rossing MA, Li CI. Hormone receptor status, tumor characteristics, and prognosis: a prospective cohort of breast cancer patients. See comment in PubMed Commons below Breast Cancer Res. 2007; 9(1): R6.

33. Cariou S, Catzavelos C, Slingerland JM. Prognostic implications of expression of the cell cycle inhibitor protein p27Kip1. Breast Cancer Res Treat. 1998; 52(1-3): 29-41.

34. Roy PG, Thompson AM. Cyclin D1 and breast cancer. Breast. 2006; 15(6): 718-727.

35. Albain KS, Alfred DC, Clark GM. Breast cancer outcome and predictors of outcome: are then age differentials? JNCI Monographs 1994; 16: $35-42$.

36. Anders CK, Hsu DS, Broadwater G, Acharya CR, Foekens JA, Zhang Y, et al. Young age at diagnosis correlates with worse prognosis and defines a subset of breast cancers with shared patterns of gene expression. J Clin Oncol. 2008; 26(20): 3324-3330.

37. Fourquet A, Campana F, Zafrani B, Mosseri V, Vielh P, Durand JC, et al. Prognostic factors of breast recurrence in the conservative management of early breast cancer: a 25-year follow-up. Int J Radiat Oncol Biol Phys. 1989; 17(4): 719-725.

38. Matthews RH, McNeese MD, Montague ED, Oswald MJ. Prognostic implications of age in breast cancer patients treated with tumorectomy and irradiation or with mastectomy. Int J Radiat Oncol Biol Phys. 1988; 14(4): 659-663.

39. Kurtz JM, Jacquemier J, Amalric R, Brandone H, Ayme Y, Hans D, et al. Why are local recurrences after breast-conserving therapy more frequent in younger patients? J Clin Oncol. 1990; 8(4): 591-598.

40. Bartelink H, Horiot JC, Poortmans PM, Struikmans H, Van den Bogaert $\mathrm{W}$, Fourquet A, et al. Impact of a higher radiation dose on local control and survival in breast-conserving therapy of early breast cancer: 10 year results of the randomized boost versus no boost EORTC 2288110882 trial. J Clin Oncol. 2007; 25(22): 3259-3265.

41. Early Breast Cancer Trialists' Collaborative Group (EBCTCG). Effects of chemotherapy and hormonal therapy for early breast cancer on recurrence and 15-year survival: an overview of the randomised trials. Lancet. 2005; 365(9472): 1687-1717. 